\title{
Influence of carcass abundance on estimates of mortality and assessment of population dynamics in Acartia tonsa
}

\author{
David T. Elliott ${ }^{1,2, *}$, Kam W. Tang ${ }^{1}$ \\ ${ }^{1}$ Virginia Institute of Marine Science, College of William and Mary, Gloucester Point, Virginia 23062, USA \\ ${ }^{2}$ Present address: University of Maryland Center for Environmental Science, Horn Point Laboratory, Cambridge, \\ Maryland 21613, USA
}

ABSTRACT: Using 2 yr of field data on the abundances of live and dead planktonic copepod nauplii and Acartia tonsa copepodites from the lower Chesapeake Bay, we evaluated the accuracy of calculated mortality rates and modeled population dynamics. Copepod mortality rates were estimated from field data both before and after removal of carcasses from abundance values, resulting in significantly different mortality rates. After removing carcasses, instantaneous mortality rates for nauplii varied from $<0.01 \mathrm{~d}^{-1}$ to a maximum of $0.35 \mathrm{~d}^{-1}$ (in August 2009), and for $A$. tonsa copepodites from $<0.01 \mathrm{~d}^{-1}$ in winter to $0.5 \mathrm{~d}^{-1}$ or higher in summer. A simple model was used to evaluate the effect of both uncorrected and corrected mortality rate estimates on $A$. tonsa population dynamics. Model predictions more closely matched field observations when parameterized with corrected mortality rates, indicating the importance of the abundances of live and dead organisms for field studies in zooplankton ecology. We used the same field dataset to estimate the predatory and nonpredatory components of mortality. Non-predatory mortality comprised an average of $25 \%$ of total mortality for nauplii, and $12 \%$ of total mortality for A. tonsa copepodites. Predatory mortality alone was insufficient to keep the $A$. tonsa population size under control during the growing season (from June to October), demonstrating the importance of nonpredatory mortality for A. tonsa in the lower Chesapeake Bay.

KEY WORDS: Zooplankton carcasses · Non-predatory mortality - Population dynamics - Acartia tonsa . Copepod · Chesapeake Bay

Resale or republication not permitted without written consent of the publisher

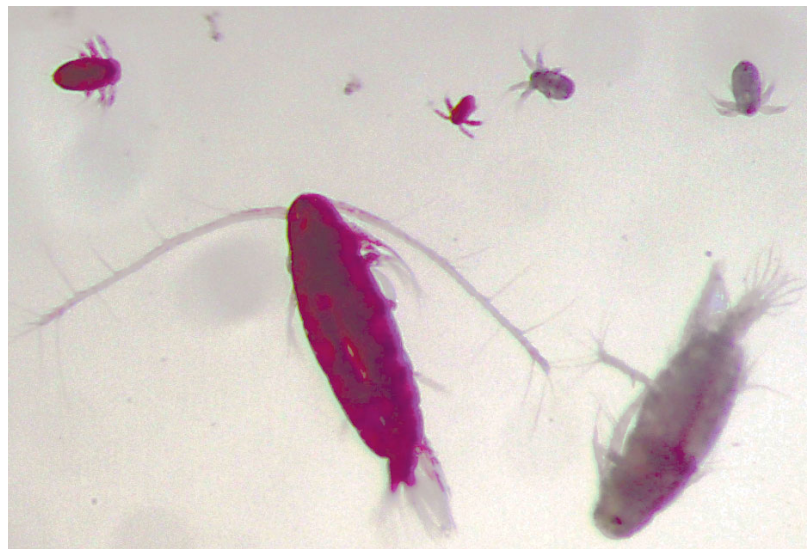

Live (red) and dead (brown) Acartia tonsa after treatment with neutral red stain (nauplii in top row, copepodites in bottom row).

Photo: David Elliott

\section{INTRODUCTION}

Mortality is a poorly constrained parameter in zooplankton population dynamics. Uncertainty in mortality rate stems from the inherent difficulties in measuring this process in situ (Ohman \& Wood 1995). However, variation in zooplankton mortality rate can drastically affect the behavior of zooplankton population dynamics models and nutrient-phytoplanktonzooplankton models (Steele \& Henderson 1992, Edwards \& Yool 2000, Plourde et al. 2009a), and a posteriori adjustments of mortality rates are often required to match model predictions to observations (Runge et al. 2004). Thus, suitable formulation of the 
mortality parameter in plankton models is a major difficulty facing plankton ecologists. To quote Runge et al. (2004, p. 431):

Accurate depiction of mortality schedules is one of the greatest challenges in the modeling of marine population dynamics. Good demographic studies of mortality in the sea are rare and in many models, mortality rates are crudely imposed as values from limited observations.

Copepods are the most abundant multicellular zooplankton form in the ocean. There are at least 3 ways to estimate copepod mortality rates from field census data: the (1) horizontal life table, (2) vertical life table (VLT), and (3) inverse-method approaches. The horizontal life table approach estimates mortality by following the development of a cohort of copepods, with the primary assumption being that physical processes do not disrupt the cohort (Aksnes et al. 1997). The VLT approach analyzes the distribution of copepod developmental stages in discrete samples, assuming that recruitment is relatively constant for the duration of the stages (Aksnes \& Ohman 1996, Aksnes et al. 1997, Hirst et al. 2007). The inverse-method approach applies known values of parameters other than mortality to population models, then estimates mortality by fitting model predictions to observed data, either varying mortality manually (tuning) or estimating it by regression (Huntley et al. 1994, Aksnes et al. 1997).

Field studies have shown that copepod mortality rates can vary spatially, temporally, interspecifically, and among developmental stages (e.g. $<0.01$ to $1.0 \mathrm{~d}^{-1}$; Eiane \& Ohman 2004, Thor et al. 2008, Plourde et al. $2009 b)$. The causes of these variations are not well understood (Twombly et al. 2007, Plourde et al. 2009a). Predatory mortality can be related to predator abundance (Ohman et al. 2008); adult copepod density (if cannibalism on young stages occurs; Peterson \& Kimmerer 1994, Ohman \& Hirche 2001); differences in prey vulnerability due to behavior, morphology, or distribution (Ohman \& Wood 1995); or the effect of water clarity on the efficiency of visual predators (Giske et al. 1994). Studies of copepod population dynamics have often focused on predatory mortality, to the exclusion of non-predatory factors. Several studies have considered non-predatory mortality due to factors such as physiological state, diet and starvation (reviewed in Carlotti et al. 2000), as well as disease and parasitism (Kimmerer \& McKinnon 1990), environmental stressors (Carpenter et al. 1974), and ageing (Rodríguez-Graña et al. 2010). There is no a priori reason to consider in situ non-predatory mortality of marine copepods as negligible. Indeed, a meta-analysis of longevity data from field and laboratory studies suggested that nonpredatory factors account for 25 to $33 \%$ of total mortality among adult copepods in the sea (Hirst \& Kiørboe 2002).
Non-predatory mortality leaves behind a carcass that, in an estuary, may remain in the water column for several days (Tang et al. 2006, Elliott et al. 2010); in the open ocean it may remain for months (Terazaki \& Wada 1988). Failure to identify carcasses in samples could skew estimates of live copepod abundance and associated ecological parameters. For example, if one were to estimate copepod production from abundance data on a single day, assuming that all collected animals were alive, the true production would be overestimated by a factor of $\left(1 / p_{\text {live }}\right)^{g}$, where $p_{\text {live }}$ is the proportion actually alive on that day and $g$ is the number of generations over which the forecast is made. Consider the common estuarine copepod species Acartia tonsa, which may have 9 generations in a year (Mauchline 1998), and is abundant in the Chesapeake Bay, USA. Multiple years of field sampling have demonstrated that from $\sim 10$ to $30 \%$ of $A$. tonsa in the lower Chesapeake Bay are carcasses (Tang et al. 2006, Elliott \& Tang 2011). Assuming a relatively conservative value of $15 \%$ dead A. tonsa (i.e. $85 \%$ alive and producing), annual copepod production forecasted from abundance data taken during the first generation of the growing season would be overestimated by a factor of $(1 / 0.85)^{9}=4.32$ if carcasses were counted as live copepods.

Identifying carcasses in plankton samples could also permit direct quantification of non-predatory mortality in situ. Copepod carcasses with injuries could be due to partial predation (assuming that injuries are not inflicted postmortem; Genin et al. 1995, Haury et al. 1995), but intact carcasses likely originate from non-predatory mortality (Weikert 1977, Tang et al. 2006). In a recent study, Elliott \& Tang (2011) described the abundances of live copepods and carcasses in the lower Chesapeake Bay over 2 yr. Carcasses were identified by neutral red vital staining, which has been rigorously tested for live/dead determinations of estuarine copepods in situ (Elliott \& Tang 2009). Elliott \& Tang (2011) found that copepod carcasses were prevalent throughout the study area, and that visibly injured carcasses were rare $(<2 \%$ of carcasses); therefore, the majority of these carcasses appeared to have resulted from non-predatory mortality.

In the present study, we used the field data from Elliott \& Tang (2011) to estimate mortality rates of copepod nauplii and Acartia tonsa copepodites with and without correcting the abundances for carcasses. Our purpose was to examine the bias in mortality rate estimates due to the inclusion of intact carcasses. We also estimated the contribution of predatory and non-predatory factors to total mortality based on abundances of intact carcasses. Finally, we used a simple population dynamics model to evaluate both the importance of identifying carcasses in samples, and the implications of predatory and non-predatory factors for the population dynamics in A. tonsa in the lower Chesapeake Bay. 


\section{METHODS}

Data for mortality estimates. Details of sample collection are reported in Elliott \& Tang (2011). Samples were collected at 12 stations in the James, Elizabeth, Rappahannock and York Rivers, all tributary to the lower Chesapeake Bay. The first 3 tributaries were sampled twice per season (winter, spring, summer, fall) in 2009, and York River stations were sampled ca. monthly from October 2007 through November 2009. Depth profiles of water temperature, salinity, dissolved oxygen, and chlorophyll a ( $\mathrm{chl}$ a) were measured with a YSI 6600 sonde. Copepod nauplii were collected by towing a $63 \mu \mathrm{m}$ mesh conical plankton net twice at each station, once horizontally near the surface for $1 \mathrm{~min}$ and once vertically from $\sim 1.5 \mathrm{~m}$ above bottom to the surface. Inspection of samples early in the study revealed that copepodites were likely undersampled by the $63 \mu \mathrm{m}$ mesh net. For this reason they were not enumerated in the $63 \mu \mathrm{m}$ mesh samples. Instead, copepodites were collected at each station by a vertical tow of a $200 \mu \mathrm{m}$ mesh net from $\sim 1.5 \mathrm{~m}$ above bottom to the surface. Plankton samples were stained with neutral red and frozen for later determination of abundance and vital status (Elliott \& Tang 2009). Counts were made for live and dead copepod nauplii (Stages NI-NIII and NIV-NVI) and Acartia tonsa copepodites (Stages CI-CIII, CIV-CV, and CVI). However, abundances of CI-CIII were omitted from mortality calculations, since a $200 \mu \mathrm{m}$ mesh net can substantially undersample younger copepodite stages for copepods the size of $A$. tonsa (Nichols \& Thompson 1991). In mortality calculations and formulation of a population dynamics model (see 'Materials and methods: Population dynamics model'), the 12 post-hatch developmental stages of the copepods were each assigned an Arabic numeral (see symbol $i$ in Table 1 ), which varied from $i=1$ for an NI nauplius to $i=12$ for an $A$. tonsa CVI copepodite.

Total mortality before and after correcting for carcasses. Using the VLT approach, we estimated mortality rates from abundance data that included intact carcasses, and separately from abundance data that included only live copepods. One of the primary assumptions in using the VLT approach is that sampling of all stages is representative of their relative abundances in situ. Stages of Acartia tonsa can have different vertical distributions, and the direction and magnitude of advection in an estuary will vary with depth. Therefore, in cases where abundance differed significantly between horizontal and vertical tows, we used only the abundances from the vertically integrated samples. In addition, to minimize any effect of differential advection of stages and to increase sample size for mortality rate estimates (Aksnes et al. 1997), we have reported mortality rates averaged across all samples collected throughout a specific tributary on any given date (from 4 to 8 replicates).

The other main assumption in applying the VLT approach is that recruitment to a stage is relatively constant over the duration of the stages for which mortality is being estimated. In a seasonal population such as Acartia tonsa in Chesapeake Bay, the presence of strong cohorts could result in violation of this assumption of constant recruitment. However, stage distribution throughout the study period showed no strong evidence of cohort structure, with fairly constant proportions of individuals in each stage except in winter (Fig. 1c). Another way to evaluate this assumption is to look at the stage-specific abundances divided by the stage duration (stage-duration-corrected abundances, SDCA). If the values of SDCA decrease across subsequent stages, then use of the VLT is supported (Hirst et al. 2007). Our data support the use of the VLT for most of the year (Fig. 2). However, both stage distribution (Fig. 1c) and SDCA (Fig. 2) suggested that the assumption of constant recruitment may be inappropriate for nauplii in the winter samples, potentially resulting in underestimation of naupliar mortality during this period. For this reason, winter naupliar mortality rates were excluded from further analysis.

VLT estimates of mortality rely on the ratio of abundances in 2 consecutive copepod stage groups. Recruitment is assumed to be constant, and the shared mortality rate for the stage groups is calculated from observed abundances and stage durations of each group (Aksnes \& Ohman 1996). Because dead individuals cannot develop to the older stage group, counting carcasses as alive in the younger group will inflate VLT mortality estimates. Conversely, counting carcasses in the older group as alive will underestimate mortality, because instances of mortality have been ignored. Hence, inclusion of abundance data on live and dead organisms for both age groups will improve VLT mortality estimates.

We used the VLT approach to calculate 2 different estimates of total mortality rates for copepod nauplii NI-NVI ( $i=1$ to 6$)$ and Acartia tonsa copepodite Stages CIV-CVI ( $i=10$ to 12 ). In the first attempt, abundance data consisted of all intact animals, including both live copepods and intact carcasses. This represents the conventional practice of ignoring the vital status of the copepods (i.e. counting intact carcasses as live individuals). In the second attempt, only live copepod abundance data were used. We refer to the first estimate as 'uncorrected total mortality' and the second estimate as 'corrected total mortality'; differences between the two indicate the bias in mortality estimates when the vital status of collected copepods is ignored. 

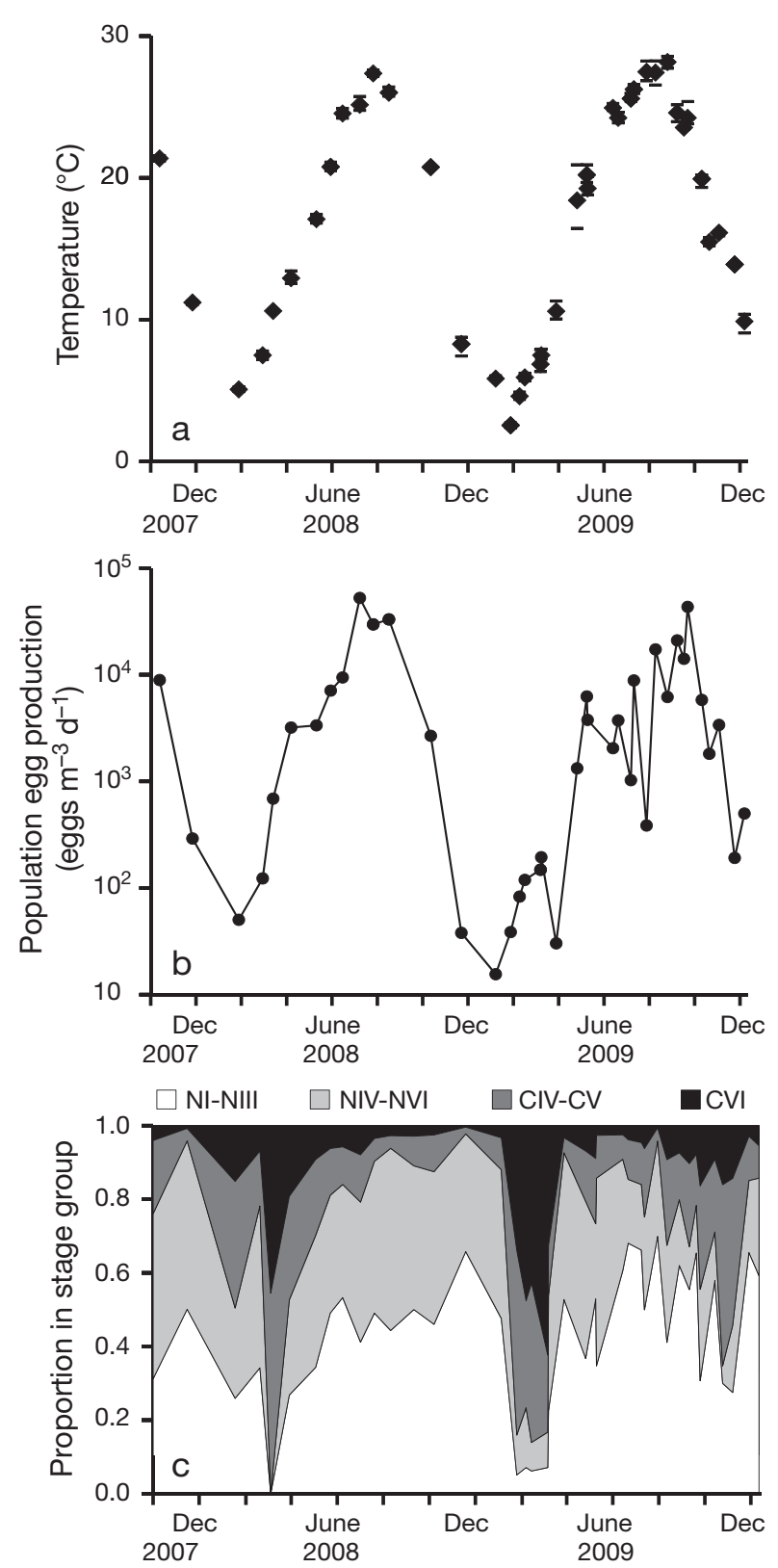

Fig. 1. Acartia tonsa. Time series of (a) mean (diamonds) and range (bars) of water temperature, (b) mean temperature-specific population egg production rate predictions (from Eq. 13 in Table 1), and (c) mean proportion observed in each developmental stage group (nauplii NI-NIII, NIV-NVI; copepodite $\mathrm{CIV}-\mathrm{CV}_{\text {; }}$ adult $\mathrm{CVI}$ ) used to estimate mortality rates (copepodite CI-CIII not used). Means are from all samples within a specific tributary on a specific date

Naupliar mortality rate is calculated as (Aksnes et al. 1997):

$$
\frac{A_{1: 3}}{A_{4: 6}}=\frac{\mathrm{e}^{m_{\mathrm{n}} \times s_{1: 3}}-1}{1-\mathrm{e}^{-m_{\mathrm{n}} \times s_{4: 6}}}
$$

where $A_{1: 3}$ is NI-NIII abundance, $A_{4: 6}$ is NIV-NVI abundance, $m_{\mathrm{n}}$ is the shared mortality rate for all naupliar stages, and $s_{1: 3}$ and $s_{4: 6}$ are the cumulative

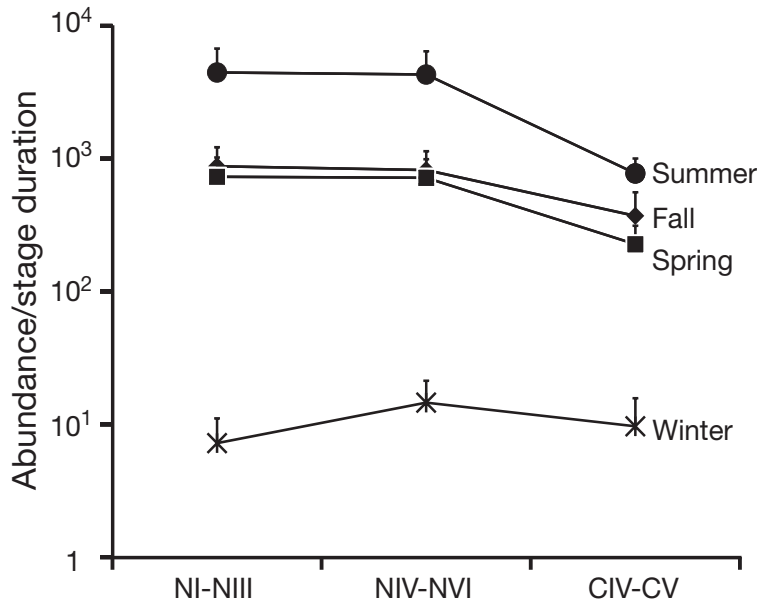

Fig. 2. Acartia tonsa. Mean stage-duration-corrected abundances (SDCA) calculated for each season over the study period. Abundances of CI-CIII are not shown since these were not used in mortality rate calculations. Error bars are $+95 \%$ confidence intervals

stage durations of NI-NIII and NIV-NVI, respectively; calculated as the number of stages ( 3 in each group) multiplied by the temperature-dependent individual stage duration (Eq. 11 in Table 1; derived from Bêlehrádek function of Leandro et al. 2006). Although nauplii were not identified to species, Acartia tonsa was the numerically dominant copepod species in $>95 \%$ of the samples, and was at least 10 times more abundant than the second most abundant species (Eurytemora affinis) in $87 \%$ of the samples (Elliott \& Tang 2011). Therefore, we assumed that the nauplii were A. tonsa. Eq. (1) was then solved iteratively for $m_{\mathrm{n}}$.

Copepodite mortality rate is calculated as (Aksnes et al. 1997):

$$
m_{\mathrm{C}}=\frac{\ln \left(\frac{A_{10: 11}}{A_{12}}+1\right)}{s_{10: 11}}
$$

where $m_{\mathrm{C}}$ is the shared mortality rate for Acartia tonsa copepodites (CIV-CVI), $A_{10: 11}$ is CIV-CV abundance, $A_{12}$ is CVI abundance, and $s_{10: 11}$ is the cumulative stage duration of $\mathrm{CIV}-\mathrm{CV}_{\text {; }}$ calculated as the number of stages (2) multiplied by the temperature-dependent individual stage duration (Eq. 11 in Table 1).

Predatory and non-predatory mortality from VLT. We also estimated the predatory and non-predatory components of mortality using the VLT approach with abundances of live copepods and carcasses. This was accomplished by treating all intact individuals (both live and dead) as survivors of predatory mortality. In this case, the VLT approach can be modified to incorporate carcasses in a manner similar to the correction for non-hatching eggs proposed by Hirst et al. (2007). The VLT equations modified to estimate predatory 
mortality are:

$$
\begin{aligned}
& \frac{A_{1: 3}}{A_{4: 6}}=\frac{1-\pi_{1} \mathrm{e}^{\left(-\delta_{\mathrm{n}} S_{1: 3}\right)}-\pi_{2} \mathrm{e}^{\left(-\delta_{\mathrm{n}} \tau\right)}}{\pi_{1} \mathrm{e}^{\left(-\delta_{\mathrm{n}}{S_{1: 3}}\right)}\left[1-\pi_{3} \mathrm{e}^{\left(-\delta_{\mathrm{n}} s_{4: 6}\right)}-\pi_{4} \mathrm{e}^{\left(-\delta_{\mathrm{n}} \tau\right)}\right]} \\
& \frac{A_{10: 11}}{A_{12}}=\frac{1-\pi_{1} \mathrm{e}^{\left(-\delta_{\mathrm{c}} s_{10: 11}\right)}-\pi_{2} \mathrm{e}^{\left(-\delta_{\mathrm{c}} \tau\right)}}{\pi_{1} \mathrm{e}^{\left(-\delta_{c} S_{10: 11}\right)}\left[1-\pi_{4} \mathrm{e}^{\left(-\delta_{c} \tau\right)}\right]}
\end{aligned}
$$

for copepod nauplii and Acartia tonsa copepodites, respectively. In these equations, the $s$ terms are stage durations as in Eqs. (1) \& (2). However, abundances (A terms) in Eqs. (3) \& (4) include live copepods and carcasses as survivors of predatory mortality. The terms $\pi_{1}$ and $\pi_{3}$ are the proportions live in the younger and older stage groups, respectively; $\pi_{2}$ and $\pi_{4}$ are the proportions dead in the younger and older groups, respectively; $\tau$ is carcass turnover time. Predatory mortality rate $\left(\delta_{\mathrm{n}}\right.$ for nauplii, $\delta_{\mathrm{c}}$ for copepodites) is solved for iteratively. Detailed derivations of Eqs. (3) \& (4) are shown in Appendix 1. Once predatory mortality rates had been calculated, non-predatory mortality rates were calculated as the difference between corrected total mortality rate (see 'Materials and methods: total mortality before and after correcting for carcasses') and predatory mortality rate. This approach to estimating non-predatory mortality rate was applied only to samples where positive values of predatory mortality were obtained.

Carcass turnover time $(\tau)$ was estimated in accordance with Elliott et al. (2010), who found that in situ turbulence in our sampling area was sufficient to retain carcasses in the water column for an extended time. Therefore, sinking losses could be neglected and $\tau$ became the time required for microbial decomposition to reduce a fresh copepod carcass down to an empty chitin carapace $(8.35 \%$ of initial dry weight; Cauchie et al. 1997), and was calculated as (see also Eq. 4 in Elliott et al. 2010):

$$
\tau=\mathrm{e}^{\left(\frac{3.83}{4.166\left(1-\mathrm{e}^{-0.008 T}\right)+0.046 \mathrm{DO}}-1.39\right)}
$$

where $\tau$ is carcass turnover time (hours from death to an empty chitin carapace), $T$ is the ambient water temperature, and DO is an indicator variable that $=0$, unless dissolved oxygen concentration is $<2 \mathrm{mg} \mathrm{l}^{-1}$, in which case it $=1$. Eq. (5) predicts very long residence times (from months to years) at the low end of our temperature range. To deal with this, estimates of $\tau$ were capped at a maximum of $7 \mathrm{~d}$, a more realistic maximum duration of carcasses in the estuarine water column (Fig. 5 in Tang et al. 2006, Table 4 in Elliott et al. 2010).

Predictive mortality functions. The relationships between mortality rates and environmental variables were explored by multiple linear least-squares regressions with stepwise selection of independent variables. Independent variables were depth-averaged water temperature, salinity, and chl $a$, depth minimum dissolved oxygen, and stratification as the difference in potential density between surface and bottom waters. Only water temperature was consistently a significant variable in these analyses, always accounting for $>98 \%$ of the regression-model-explained variability $\left(R^{2}\right)$ in mortality rates. Therefore, simple linear regressions of mortality rates versus water temperature were used to parameterize mortality in a population dynamics model (see 'Materials and methods: Population dynamics model'). We also tested for density-dependent mortality by performing linear least-squares regressions of corrected total mortality rates versus adult Acartia tonsa abundance.

Population dynamics model. A model describing Acartia tonsa population dynamics was used to evaluate the implications of (1) the uncorrected and corrected total mortality rate estimates, and (2) the predatory and non-predatory components of mortality rates. The model (Table 1) consisted of 13 coupled differential equations describing temporal change in $A$. tonsa abundances from eggs $\left(A_{\text {egg }}\right)$ through adults $\left(A_{12}\right)$. Model output was given as cumulative copepodite abundance $\left(A_{7: 12}\right)$, and was compared with archived data to evaluate model performance. Monthly mean abundances of Acartia spp. copepodites were calculated using archived Chesapeake Bay Program (CBP) mesozooplankton monitoring project data (www.chesapeakebay.net/data_plankton. aspx) from January 2000 to November 2002 (York River stations RET4.3 and WE4.2). Data before 2000 were omitted due to underestimation of mesozooplankton abundances prior to that year (Chesapeake Bay Program 2000), and the monitoring was terminated after 2002.

The initial abundance values in the model (Day 0, Table 1) were approximated from CBP abundances in early January 2000-2002. However, the model behavior was insensitive to these initial abundances. Changing initial abundances influenced the overall magnitude of predicted abundances, but not the annual pattern or timing of population growth and decline. Modeled rates of change in abundance of each developmental stage ( $\mathrm{d} A / \mathrm{d} t_{i}$ Eqs. $7-9$ in Table 1$)$ were based on development rates $(D)$ and mortality rates $(m)$. Stagespecific development rates for eggs through $\mathrm{CV}\left(D_{i i}\right.$ Eq. 12 in Table 1) were the reciprocal of individual stage durations $\left(s_{i i}\right.$ Eqs. 10 and 11 in Table 1). These stage durations came from Bêlehrádek functions describing Acartia tonsa egg and post-hatch development times as related to temperature (McLaren et al. 1969, Leandro et al. 2006). The equivalent of development rate for adults $\left(D_{12}\right)$ was not used to predict their abundance (Eq. 9 in Table 1), since adults remain as CVI until death. Instead, $D_{12}$ was the adult female egg production rate, reported as a unimodal function of temperature (Holste \& Peck 2005; Eq. 13 in Table 1), and was used to predict gains to the egg stage (Eq. 7 in Table 1). Adult sex ratio was specified to be $63 \%$ 
Table 1. Acartia tonsa. Formulations, parameterizations, and sources of data used in population dynamics model. CBP: Chesapeake Bay Program

\begin{tabular}{|c|c|c|c|c|c|}
\hline & Symbol & Units & Eq. no. & Value & Source \\
\hline \multicolumn{6}{|l|}{ Model organization: } \\
\hline Day in model & Day & $\mathrm{d}$ & & $=1$ to 365 & \\
\hline Temperature & $T$ & ${ }^{\circ} \mathrm{C}$ & (6) & $=A+B \times \cos [2 \pi($ Day $-C) / 365]$ & \\
\hline Developmental stage & $i$ & & & $\begin{aligned}= & \text { egg }(\text { egg }) ; \text { nauplii NI-NVI }(1: 6)_{i} \\
& \text { copepodites CI-CV }(7: 11) ; \text { adult CVI (12) }\end{aligned}$ & \\
\hline Day 0 abundances & $A_{i}$ & ind. $\mathrm{m}^{-3}$ & & $=500$ nauplii and 200 copepodites per stage & CBP database \\
\hline $\begin{array}{l}\text { Governing equations: } \\
\text { Rate of change }(i=\text { egg) } \\
\text { Rate of change }(i=1 \text { to } 11) \\
\text { Rate of change }(i=12)\end{array}$ & $\begin{array}{l}\mathrm{d} A_{i} / \mathrm{d} t \\
\mathrm{~d} A_{i} / \mathrm{d} t \\
\mathrm{~d} A_{i} / \mathrm{d} t\end{array}$ & $\begin{array}{l}\text { ind. } \mathrm{m}^{-3} \mathrm{~d}^{-1} \\
\text { ind. } \mathrm{m}^{-3} \mathrm{~d}^{-1} \\
\text { ind. } \mathrm{m}^{-3} \mathrm{~d}^{-1}\end{array}$ & $\begin{array}{l}(7) \\
(8) \\
(9)\end{array}$ & $\begin{array}{l}=0.63 \times A_{12}\left(D_{12}\right)-A_{\text {egg }}\left(D_{\text {egg }}\right)-A_{\text {egg }}\left(m_{\text {egg }}\right) \\
=A_{i-1}\left(D_{i-1}\right)-A_{i}\left(D_{i}\right)-A_{i}\left(m_{i}\right) \\
=A_{11}\left(D_{11}\right)-A_{12}\left(m_{12}\right)\end{array}$ & \\
\hline \multicolumn{6}{|l|}{ Specific formulations: } \\
\hline Stage duration $(i=$ egg $)$ & $S_{i}$ & $\mathrm{~d}$ & $(10)$ & $=489(T-1.8)^{-2.05}$ & McLaren et al. (1969) \\
\hline Stage duration ( $i=1$ to 11$)$ & $S_{i}$ & $\mathrm{~d}$ & (11) & $=(a \times 5491.85 / 11) \times(T+0.96)^{-2.05}$ & Leandro et al. (2006) \\
\hline $\begin{array}{l}\text { Mean deviation of stage } \\
\text { durations from isochronal }\end{array}$ & $a$ & & & $\begin{aligned}= & 1.05 \text { for NI-NIII; } 0.81 \text { for NIV-NVI } \\
& 0.92 \text { for CI-CIII; } 1.32 \text { for CIV-CV }\end{aligned}$ & $\begin{array}{l}\text { Derived from Table } 1 \\
\text { in Leandro et al. (2006) }\end{array}$ \\
\hline Development rate $(i=$ egg to 11 & 1) $D_{i}$ & $\mathrm{~d}^{-1}$ & $(12)$ & $=1 / s_{i}$ & \\
\hline Adult egg production rate & $D_{12}$ & $d^{-1}$ & (13) & $=50.9 \times((34-T) / 9.22)^{3.95} \times \mathrm{e}^{[(3.95 \times(T-24.78)) / 9.22]}$ & Holste \& Peck (2006) \\
\hline Mortality rate $(i=$ egg $)$ & $m_{i}$ & $\mathrm{~d}^{-1}$ & (14) & $=\mathrm{e}^{(0.0725 T-1.112)}$ & Hirst \& Kiørboe (2002) \\
\hline Mortality rate ( $i=1$ to 12 ) & $m_{i}$ & $d^{-1}$ & & Specific to model run & Present study \\
\hline
\end{tabular}

female, derived as the weighted (by $n$ ) average of all Acartia spp. sex ratios reported in Appendix C of Hirst \& Kiørboe (2002). The possibility of food limitation on egg production rate was also evaluated. In an early version of the model, predictions of egg production were constrained based on the negative exponential relationship between chl $a$ and $A$. tonsa egg production in Narragansett Bay (Durbin et al. 1983; their Fig. 7). However, inclusion of this food limitation term had little effect on the model predictions because copepod growth in Chesapeake Bay is not usually food-limited (Kemp et al. 2005). In addition, food limitation would influence all model runs equally and independently of the mortality term used, making it irrelevant to our goal of evaluating the population effects of different mortality estimates. Therefore, results of the model based only on temperature are presented here.

The model was run for $365 \mathrm{~d}$, with temperature determined each day from a cosine function (Eq. 6 in Table 1). This function was fit by non-linear regression to York River CBP water temperature data for 2000 to 2002, estimating parameters iteratively $(A=16.133, B=$ -11.132, and $C=-28.076)$. Naupliar and copepodite mortalities $\left(m_{1: 12}\right)$ were parameterized with the regression equations describing mortality rates versus temperature, and mortality rates derived for CIV-CVI were applied to all copepodite stages. At the low end of our temperature scale these regressions predicted negative mortalities, in which case model mortality rate was set to zero. Because data on egg abundances were not available, model egg mortality $\left(m_{\text {egg }}\right)$ was predicted using a published regression of egg mortal- ity versus temperature for broadcast-spawning copepods (Hirst \& Kiørboe 2002; Eq. 14 in Table 1).

\section{RESULTS}

\section{Field data}

Water temperature varied cyclically during both years of the study, with annual maxima near $28^{\circ} \mathrm{C}$ in July and August (Fig. 1a). Predicted population egg production rate also showed an annual cycle, peaking in July through September, with lowest values in January of both years (Fig. 1b). Overall, estimated population egg production rates were consistently high (>1000 eggs $\mathrm{m}^{-3} \mathrm{~d}^{-1}$ ) from April through October. The proportions of individuals in each developmental stage group were similar throughout most of the study period, except during the winter when the relative abundance of adults increased markedly (Fig. 1c). SDCA declined across consecutive stage groups during spring, summer, and fall, although only slightly between NI-NIII and NIV-NVI (Fig. 2). Again, the exception was seen in winter samples when SDCA of NIV-NVI were higher than NI-NIII.

\section{Total mortality}

Total mortality rates varied in a cyclic manner annually, peaking in the summer (Fig. 3). Corrected total mortality for nauplii varied from near $0.0 \mathrm{~d}^{-1}$ in the fall 

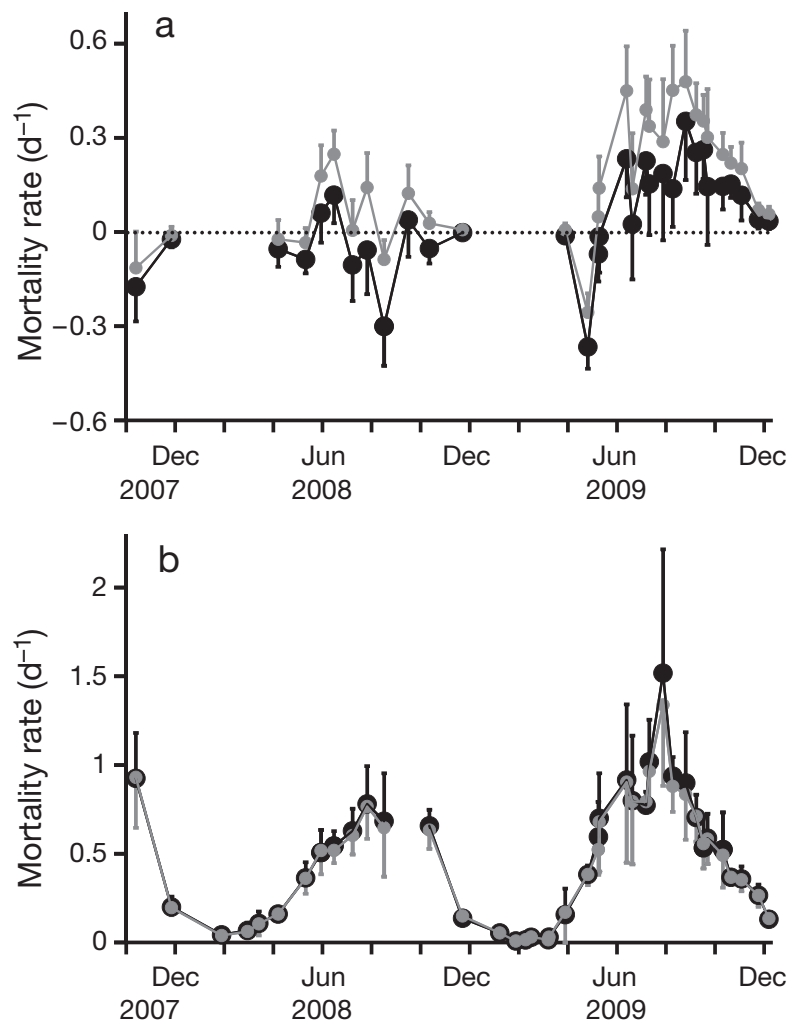

Fig. 3. Acartia tonsa. Time series of uncorrected (gray symbols) and corrected (black symbols) total mortality rate estimates for (a) nauplii and (b) copepodites. Error bars are $\pm 95 \%$ confidence intervals in a specific tributary on a specific date

and spring to a maximum of $0.12 \mathrm{~d}^{-1}$ in June 2008 and $0.35 \mathrm{~d}^{-1}$ in August 2009 (Fig. 3a). Incidences of negative mortality rate were likely a result of violation of VLT assumption(s) on those dates, such as the assumption of representative sampling of each developmental stage, or constant recruitment over the duration of all naupliar stages. Corrected total mortality for Acartia tonsa copepodites was near $0.0 \mathrm{~d}^{-1}$ in the winter, and ca. $0.7 \mathrm{~d}^{-1}$ in summer 2008 and $0.9 \mathrm{~d}^{-1}$ in summer 2009, with a maximum of $1.52 \mathrm{~d}^{-1}$ in July 2009 (Fig. 3b). Corrected mortality rates were significantly different from uncorrected rates, both for nauplii and $A$. tonsa copepodites (paired $t$-tests: p < 0.0005 and $p=0.002$, respectively). The difference was obvious for nauplii, where uncorrected mortality rates were consistently higher than corrected rates (Fig. 3a). Mortality rate estimates for A. tonsa copepodites were only slightly influenced by the inclusion of carcasses (Fig. 3b). This was due to the fact that a similar percentage of carcasses was found in both CIV-CV and CVI copepodite stage groups, meaning that carcasses caused only a small bias in the abundance ratio $\left(A_{10: 11} / A_{12}\right)$ that was used to estimate mortality by the VLT approach.
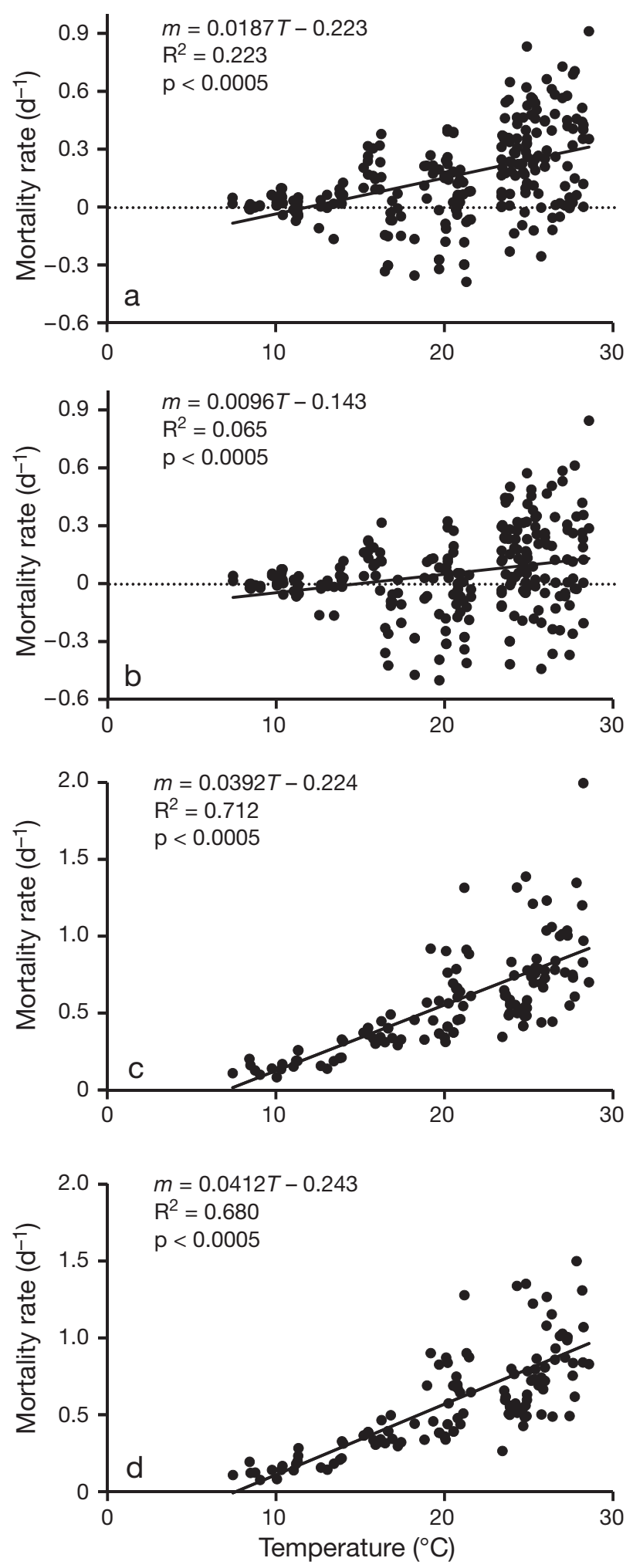

Fig. 4. Acartia tonsa. Regression analysis of temperature versus total copepod mortality rates for (a) nauplii uncorrected for carcasses, (b) nauplii after correcting for carcasses, (c) copepodites uncorrected for carcasses, and (d) copepodites after correcting for carcasses (all from vertical life table

[VLT] approach). Regression statistics are also shown 
In the stepwise multiple regressions, water temperature predicted the vast majority of explained variation in mortality rates, being responsible for $>98 \%$ of each model $\mathrm{R}^{2}$ value. Based on simple linear regression, both uncorrected and corrected total mortality rates increased significantly with increasing water temperature (Fig. 4). Density-dependent mortality was not observed, since mortality rates were not significantly related to Acartia tonsa adult abundances (nauplii $\mathrm{R}^{2}<$ $0.0005, \mathrm{p}=0.663$; copepodites $\mathrm{R}^{2}<0.0005, \mathrm{p}=0.401$ ).

The equations describing mortality versus temperature (Fig. 4) were used to parameterize mortality in the population model (Table 1). For comparative purposes, the model was also run with a fixed mortality rate, calculated as the average of corrected total mortalities for 2007 to 2009 (Fig. 3). Fixed mortality resulted in low abundances until late July, when the population quickly grew above realistic abundances $\left(>10^{8}\right.$ ind. $\mathrm{m}^{-3}$ ) before decreasing again in November and December (data not shown). Predictions based on uncorrected total mortality rates showed population growth until March, when the population began to decline and approached extinction by June (Fig. 5). In a sensitivity analysis, even when we allowed the slope of the temperature-mortality regression equations to vary randomly by up to $200 \%$, the predicted abundances still never reached 1000 ind. $\mathrm{m}^{-3}$ in summer-fall (50 trials, data not shown).

Predictions based on corrected total mortality rates most closely matched the CBP observed abundances, and the population displayed a typical annual cycle rather than going extinct or growing to unrealistic abundances (Fig. 5). It is worth noting that a small difference between corrected and uncorrected mortality

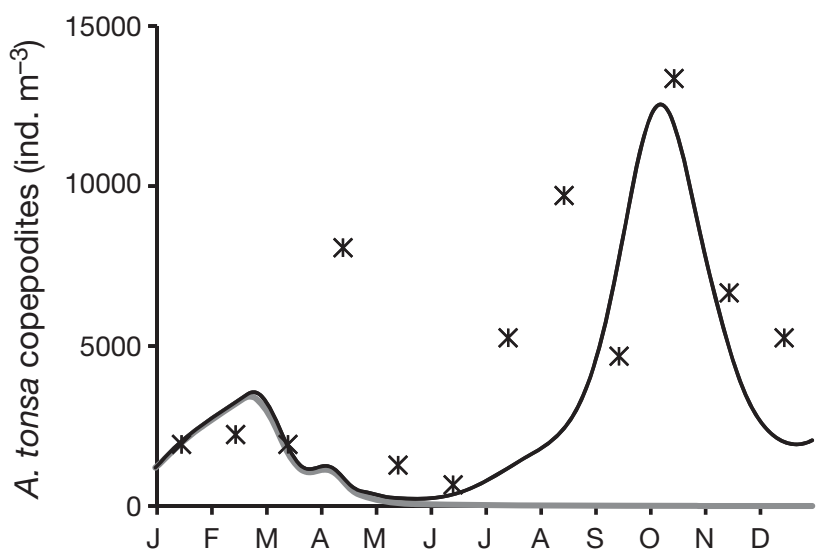

Fig. 5. Acartia tonsa. Population dynamics model predictions of abundance of copepodites using different mortality formulations. Solid gray line $=$ uncorrected total mortality (regression equations from Fig. $4 \mathrm{a}, \mathrm{c})$; solid black line = corrected total mortality (regression equations from Fig. 4 b,d); asterisks = monthly mean abundances of Acartia spp. copepodites from Chesapeake Bay Program rates (Fig. 3) led to substantially different population development, especially later in the year. This difference likely occurred because the higher uncorrected naupliar mortality rates resulted in lower adult abundances, and this effect reverberated through multiple generations in our model run. Hence, model predictions that relied on only live copepod abundances to estimate mortality differed substantially from, and were more realistic than, predictions made without abundance data for live and dead organisms.

\section{Predatory and non-predatory components of mortality}

Non-predatory mortality rates varied in a cyclic annual manner, with highest values in the late spring and summer (Fig. 6). Naupliar non-predatory mortality ranged from $0.0 \mathrm{~d}^{-1}$ to $0.1 \mathrm{~d}^{-1}$ throughout the study period, accounting for a mean of $25 \%$ of corrected total mortality. Copepodite non-predatory mortality ranged from $0.0 \mathrm{~d}^{-1}$ to a maximum of $0.12 \mathrm{~d}^{-1}$ in 2008 and $0.34 \mathrm{~d}^{-1}$ in 2009 , accounting for a mean of $12 \%$ of corrected total mortality. Both predatory and nonpredatory components of mortality were significantly and positively related to water temperature (Fig. 7).
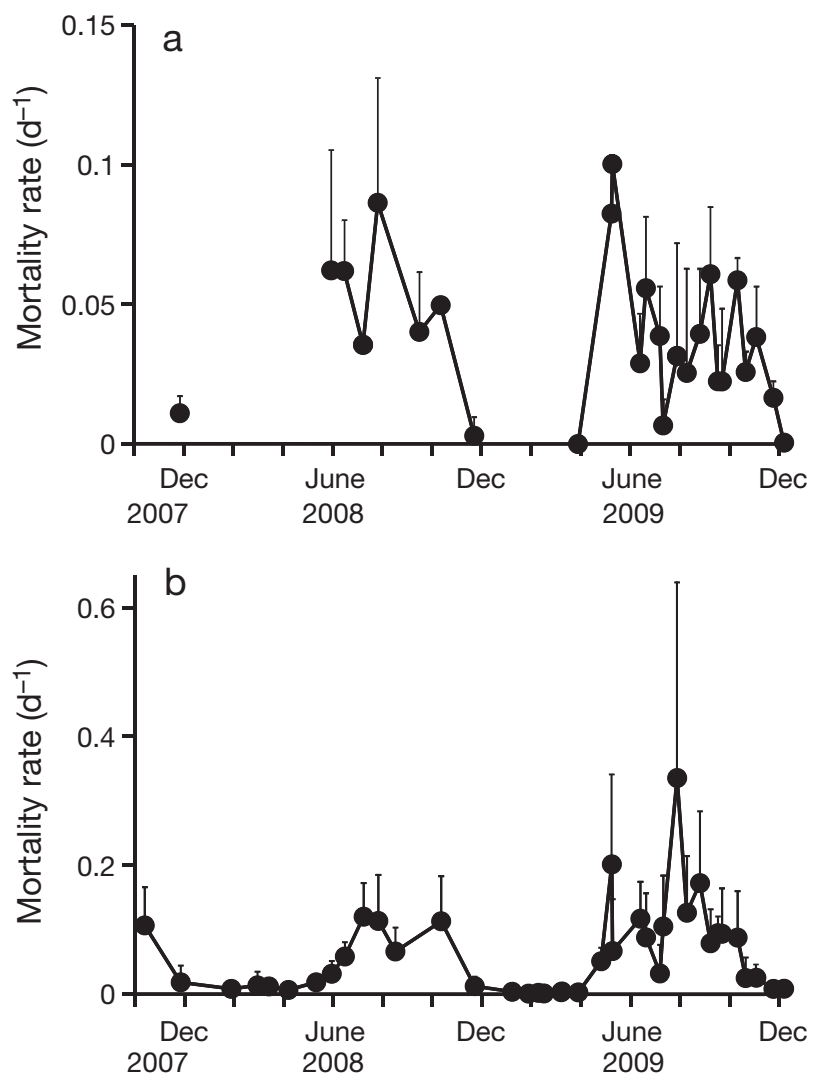

Fig. 6. Acartia tonsa. Time series of non-predatory mortality rates for (a) nauplii and (b) copepodites. Error bars are $+95 \%$ confidence intervals in a specific tributary on a specific date 

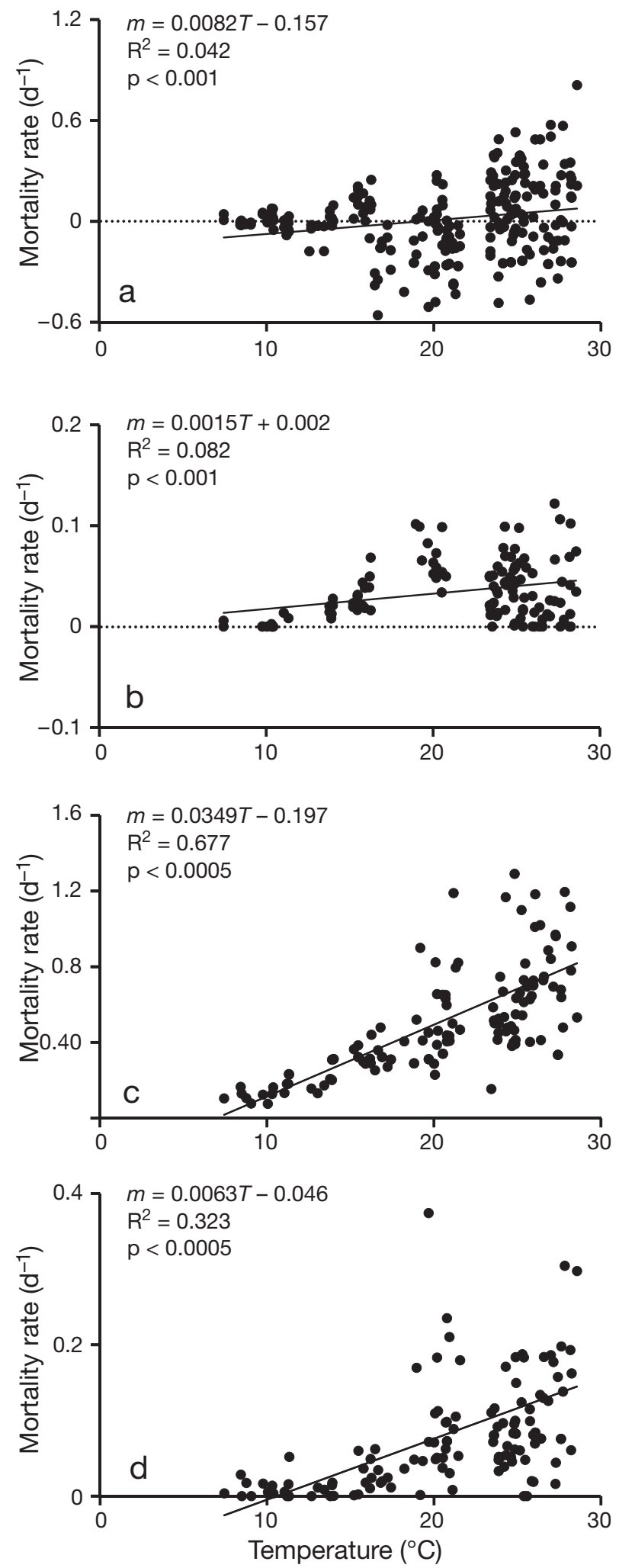

Fig. 7. Acartia tonsa. Regression analysis of temperature versus naupliar (a) predatory and (b) non-predatory mortality rates, and copepodite (c) predatory and (d) non-predatory mortality rates (all from vertical life table [VLT] approach). Regression statistics are also shown

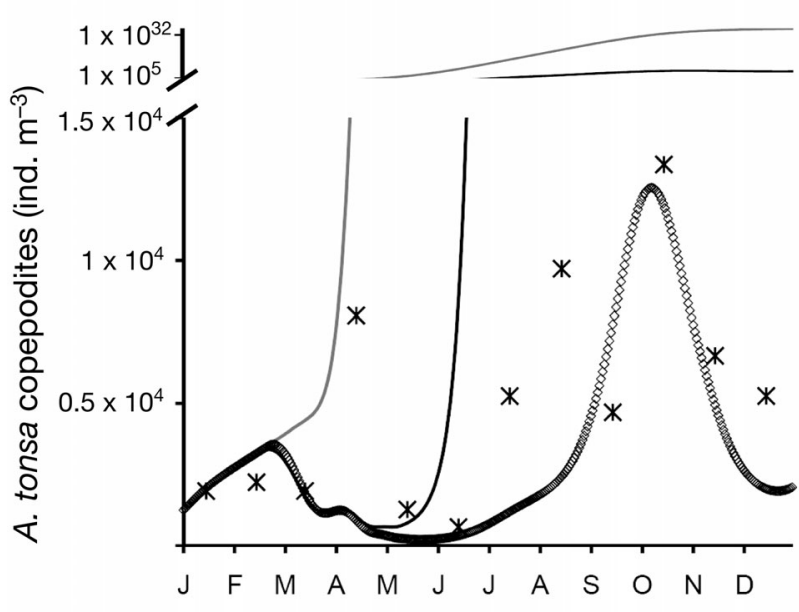

Fig. 8. Acartia tonsa. Predictions of abundance of copepodites, using different components of mortality. Open diamonds $=$ corrected total mortality (as in Fig. 5); solid black line $=$ predatory mortality only (regression equations from Fig. $7 \mathrm{a}, \mathrm{c})$; solid gray line $=$ non-predatory mortality only (regression equations from Fig. 7b,d); asterisks = monthly mean abundances of Acartia spp. copepodites from Chesapeake Bay Program

To evaluate the importance of predatory and nonpredatory mortalities for Acartia tonsa population dynamics, the respective regression equations (Fig. 7) were used to parameterize the mortality term in the population model (Table 1). When only non-predatory mortality was considered, predicted abundance increased rapidly in the spring when egg production and development rates increased with temperature (Fig. 8). When only predatory mortality was considered, model prediction agreed fairly well with archived CBP data in winter and early spring, after which the predicted abundances increased unrealistically before stabilizing near $5 \times 10^{9}$ ind. $\mathrm{m}^{-3}$ (in late fall; Fig. 8). Only when non-predatory and predatory mortality rates were considered together did the model closely reproduce the CBP observations (Fig. 8). Thus, while non-predatory mortality alone did not explain observed $A$. tonsa population behavior, it was critical to the overall population dynamics, particularly in the late spring and summer months when predatory mortality alone failed to keep population size under control.

\section{DISCUSSION}

Quantification of the abundances of live and dead zooplankton in field samples is not commonly done because of the difficulty in identifying carcasses and the extra sample processing time required. Nevertheless one may ask: Is it necessary to distinguish between live and dead zooplankton in field samples? Previous 
studies have shown that zooplankton carcasses can be prevalent in both marine and freshwater environments, accounting for anywhere from 4 to $69 \%$ of collected animals (reviewed in Tang et al. 2009). In the present study, we directly demonstrated that failure to identify copepod carcasses can lead to errors when estimating population parameters such as mortality rates (Fig. 3), which could then create bias in understanding copepod population dynamics (Fig. 5). Some researchers may moderate such bias by discounting visibly decomposed carcasses. However, carcasses remain intact and similar in appearance to live animals for hours to days after death (Tang et al. 2006). It is therefore clear that quantifying the abundances of live and dead organisms in field samples is an important consideration in zooplankton studies. The use of neutral red and other staining methods should allow researchers to reliably identify intact zooplankton carcasses in field samples with relative ease (Bickel et al. 2009, Elliott \& Tang 2009).

In our study, mortality rates of copepod nauplii and Acartia tonsa copepodites were more closely correlated with temperature (Fig. 4) than with any other measured variable, including adult population density. Life history theory suggests that mortality risk increases at higher temperatures, but is offset by the faster development to reproductive stage (Myers \& Runge 1983, Kiørboe \& Hirst 2008). Previous studies have found that mortality rates scaled significantly with temperature (Hirst \& Kiørboe 2002, Hirst et al. 2007, Plourde et al. $2009 b)$. Predator abundance and predation rate are likely to be temperature-dependent (Myers \& Runge 1983), and higher temperature could also increase disease and parasitism in natural populations (Harvell et al. 2002). For poikilotherms, such as copepods, temperature can directly affect metabolic processes; higher temperatures increase starvation risk (Tsuda 1994) and decrease maximum lifespan (Gophen 1976).

In Atlantic estuaries, including the Chesapeake Bay, the growth season for Acartia tonsa begins when water temperature reaches $15^{\circ} \mathrm{C}$ (Jeffries 1962, Elliott \& Tang 2011). At these temperatures our regression models (Figs. 4 \& 7) predicted that non-predatory mortality represented a median of 14 and $49 \%$ of corrected total mortality for $A$. tonsa copepodites and copepod nauplii, respectively. These results were consistent with those of Hirst \& Kiørboe (2002), who concluded that non-predatory mortality accounted for ca. one-quarter to one-third of copepod mortality globally.

Our population dynamics model indicated that in June-July the increase in Acartia tonsa population growth potential exceeded the increase in predation mortality, and predatory mortality alone could not keep abundances in check (Fig. 8). During spring and summer, the 3 dominant planktivores in Chesapeake
Bay are ctenophores (especially Mnemiopsis leidyi), the sea nettle Chrysaora quinquecirrha, and the bay anchovy Anchoa mitchilli (Baird \& Ulanowicz 1989). Although sea nettles prey on copepods, they can also exert top-down control on ctenophores, and the net result of high sea nettle abundances in the summer may be to decrease predation pressure on $A$. tonsa (Purcell \& Decker 2005). The magnitude of planktivory by bay anchovy in Chesapeake Bay does not increase substantially until later in the summer, ca. August (Wang \& Houde 1995). Therefore, between June and July, non-predatory mortality likely supplements predatory mortality in a manner that is critical for controlling the population of $A$. tonsa.

As discussed above, several non-predatory mortality risk factors might increase with temperature, including disease and parasitism, starvation, and ageing. In addition, hypoxic conditions can cause Acartia tonsa mortality (Stalder \& Marcus 1997). Low oxygen conditions begin in Chesapeake Bay around June and persist throughout the summer (Hagy et al. 2004), corresponding to the period when non-predatory mortality becomes critical (Fig. 8). Although Elliott \& Tang (2011) rarely observed hypoxia in the field, that study did not focus on areas known to be seasonally hypoxic, and the sampling protocol may have overlooked localized patches of hypoxic deepwater. Mortality rates of a comparable magnitude to ours were reported for summer A. tonsa populations in Mariager Fjord, Denmark, which also experiences severe seasonal oxygen depletion (Tiselius et al. 2008).

This study demonstrated the importance of abundance data on live and dead organisms for the proper understanding of zooplankton population dynamics and related ecological processes. We estimated predatory and non-predatory mortalities of copepods in Chesapeake Bay based directly on field observations of live/dead copepod composition, and the results agreed well with the previous indirect estimates of Hirst \& Kiørboe (2002). Although non-predatory mortality generally accounted for less than half of total mortality, it was crucial for obtaining realistic abundance predictions from the population dynamics model. Future studies should evaluate the importance of non-predatory mortality for other zooplankton populations and other locations. Research is also needed to identify the main causes of non-predatory mortality, especially for nauplii, which suffer a substantial proportion of mortality from non-predatory factors. In combination with an improved understanding of what regulates predatory mortality, research on nonpredatory mortality will contribute to a mechanistic and predictive representation of the mortality term that is so critical to understanding how copepod populations vary in nature. 
Acknowledgments. This research was funded by US National Science Foundation (NSF) OCE-0814558, awarded to K.W.T. D.T.E. also received financial support from NSF GK-12 (DGE0840804, awarded to K.W.T). Three anonymous reviewers contributed substantially to the improvement of the manuscript. This paper is Contribution No. 3150 of the Virginia Institute of Marine Science, College of William and Mary.

\section{LITERATURE CITED}

Aksnes DL, Ohman MD (1996) A vertical life table approach to zooplankton mortality estimation. Limnol Oceanogr 41: 1461-1469

Aksnes DL, Miller CB, Ohman MD, Wood SN (1997) Estimation techniques used in studies of copepod population dynamics: a review of underlying assumptions. Sarsia 82:279-296

Baird D, Ulanowicz RE (1989) The seasonal dynamics of the Chesapeake Bay ecosystem. Ecol Monogr 59:329-364

> Bickel SL, Tang KW, Grossart HP (2009) Use of aniline blue to distinguish live and dead crustacean zooplankton composition in freshwaters. Freshw Biol 54:971-981

Carlotti F, Giske J, Werner F (2000) Modeling zooplankton dynamics. In: Harris R, Wiebe P, Lenz J, Skjoldal H, Huntley $\mathrm{M}$ (eds) ICES zooplankton methodology manual. Academic Press, London, p 572-667

Carpenter EJ, Peck BB, Anderson SJ (1974) Survival of copepods passing through a nuclear power station on northeastern Long Island Sound, USA. Mar Biol 24:49-55

Cauchie HM, Murugan G, Thomé JP, Dumont HJ (1997) Intraand interspecific variation in the chitin content of some anostracans. Hydrobiol 359:223-228

Chesapeake Bay Program (2000) The 2000 user's guide to Chesapeake Bay Program biological and living resources monitoring data. US Environmental Protection Agency, Washington, DC

> Durbin EG, Durbin AG, Smayda TJ, Verity PG (1983) Food limitation of production by adult Acartia tonsa in Narragansett Bay, Rhode Island. Limnol Oceanogr 28:1199-1213

Edwards AM, Yool A (2000) The role of higher predation in plankton population models. J Plankton Res 22:1085-1112

Eiane K, Ohman MD (2004) Stage-specific mortality of Calanus finmarchicus, Pseudocalanus elongatus and Oithona similis on Fladen Ground, North Sea, during a spring bloom. Mar Ecol Prog Ser 268:183-193

Elliott DT, Tang KW (2009) Simple staining method for differentiating live and dead marine zooplankton in field samples. Limnol Oceanogr Methods 7:585-594

Elliott DT, Tang KW (2011) Spatial and temporal distributions of live and dead copepods in the lower Chesapeake Bay (Virginia, USA). Estuaries Coasts 34: doi: 10.1007/s12237011-9380-z

Elliott DT, Harris CK, Tang KW (2010) Dead in the water: the fate of copepod carcasses in the York River estuary, Virginia. Limnol Oceanogr 55:1821-1834

Genin A, Gal G, Haury L (1995) Copepod carcasses in the ocean. II. Near coral reefs. Mar Ecol Prog Ser 123:65-71

Giske J, Aksnes DL, Fiksen O (1994) Visual predators, environmental variables and zooplankton mortality risk. Vie Milieu $44: 1-9$

> Gophen M (1976) Temperature effect on lifespan, metabolism, and development time of Mesocyclops leuckarti (Claus). Oecologia 25:271-277

> Hagy JD, Boynton WR, Keefe CW, Wood KV (2004) Hypoxia in Chesapeake Bay, 1950-2001: long-term change in relation to nutrient loading and river flow. Estuaries Coasts 27: 634-658

Harvell CD, Mitchell CE, Ward JR, Altizer S, Dobson AP,
Ostfeld RS, Samuel MD (2002) Climate warming and disease risks for terrestrial and marine biota. Science 296:2158-2162 - Haury L, Fey C, Gal G, Hobday A, Genin A (1995) Copepod carcasses in the ocean. I. Over seamounts. Mar Ecol Prog Ser 123:57-63

- Hirst AG, Kiørboe T (2002) Mortality of marine planktonic copepods: global rates and patterns. Mar Ecol Prog Ser 230: 195-209

> Hirst AG, Bonnet D, Harris RP (2007) Seasonal dynamics and mortality rates of Calanus helgolandicus over two years at a station in the English Channel. Mar Ecol Prog Ser 340: 189-205

- Holste L, Peck MA (2005) The effects of temperature and salinity on egg production and hatching success of Baltic Acartia tonsa (Copepoda: Calanoida): a laboratory investigation. Mar Biol 148:1061-1070

> Huntley ME, Zhou M, Lopez MDG (1994) Calanoides acutus in Gerlache Strait, Antarctica II: solving an inverse problem in population dynamics. Deep-Sea Res II 41:209-227

Jeffries HP (1962) Succession of two Acartia species in estuaries. Limnol Oceanogr 7:354-364

> Kemp WM, Boynton WR, Adolf JE, Boesch DF and others (2005) Eutrophication of Chesapeake Bay: historical trends and ecological interactions. Mar Ecol Prog Ser 303:1-29

Kimmerer WJ, McKinnon AD (1990) High mortality in a copepod population caused by a parasitic dinoflagellate. Mar Biol 107:449-452

Kiørboe T, Hirst AG (2008) Optimal development time in pelagic copepods. Mar Ecol Prog Ser 367:15-22

> Leandro SM, Tiselius P, Queiroga H (2006) Growth and development of nauplii and copepodites of the estuarine copepod Acartia tonsa from southern Europe (Ria de Aveiro, Portugal) under saturating food conditions. Mar Biol 150: $121-129$

Mauchline J (1998) The biology of calanoid copepods. Adv Mar Biol 33

McLaren IA, Corkett CJ, Zillioux EJ (1969) Temperature adaptations of copepod eggs from the arctic to the tropics. Biol Bull 137:486-493

Myers RA, Runge JA (1983) Predictions of seasonal natural mortality rates in a copepod population using life-history theory. Mar Ecol Prog Ser 11:189-194

Nichols JH, Thompson AB (1991) Mesh selection of copepodite and nauplius stages of four calanoid copepod species. J Plankton Res 13:661-671

Ohman MD, Hirche HJ (2001) Density-dependent mortality in an oceanic copepod population. Nature 412:638-641

> Ohman MD, Wood SN (1995) The inevitability of mortality. ICES J Mar Sci 52:517-522

> Ohman MD, Durbin EG, Runge JA, Sullivan BK, Field DB (2008) Relationship of predation potential to mortality of Calanus finmarchicus on Georges Bank, northwest Atlantic. Limnol Oceanogr 53:1643-1655

> Peterson WT, Kimmerer WJ (1994) Processes controlling recruitment of the marine calanoid copepod Temora longicornis in Long Island Sound: egg production, egg mortality, and cohort survival rates. Limnol Oceanogr 39:1594-1605

> Plourde S, Maps F, Joly P (2009a) Mortality and survival in early stages control recruitment in Calanus finmarchicus. J Plankton Res 31:371-388

Plourde S, Pepin P, Head EJH (2009b) Long-term seasonal and spatial patterns in mortality and survival of Calanus finmarchicus across the Atlantic Zone Monitoring Programme region, northwest Atlantic. ICES J Mar Sci 66:1942-1958

> Purcell JE, Decker MB (2005) Effects of climate on relative predation by scyphomedusae and ctenophores on copepods in Chesapeake Bay during 1987-2000. Limnol Oceanogr 50: 376-387 
Rodríguez-Graña L, Calliari D, Tiselius P, Hansen BW, Sköld HN (2010) Gender-specific ageing and non-Mendelian inheritance of oxidative damage in marine copepods. Mar Ecol Prog Ser 401:1-13

Runge JA, Franks PJS, Gentleman WC, Megrey BA, Rose KA, Werner FE, Zakardjian B (2004) Diagnosis and prediction of variability in secondary production and fish recruitment processes: developments in physical-biological modeling. In: Robinson AR, Brink KH (eds) The sea, Vol 13. Harvard University Press, Cambridge, MA, p 413-473

Stalder LC, Marcus NH (1997) Zooplankton responses to hypoxia: behavioral patterns and survival of three species of calanoid copepods. Mar Biol 127:599-607

Steele JH, Henderson EW (1992) The role of predation in plankton models. J Plankton Res 14:157-172

Tang KW, Freund CS, Schweitzer CL (2006) Occurrence of copepod carcasses in the lower Chesapeake Bay and their decomposition by ambient microbes. Estuar Coast Shelf Sci 68:499-508

Tang KW, Bickel SL, Dziallas C, Grossart HP (2009) Microbial activities accompanying decomposition of cladoceran and copepod carcasses under different environmental condi- tions. Aquat Microb Ecol 57:89-100

Terazaki M, Wada M (1988) Occurrence of large numbers of carcasses of the large, grazing copepod Calanus cristatus from the Japan Sea. Mar Biol 97:177-183

Thor P, Nielsen TG, Tiselius P (2008) Mortality rates of epipelagic copepods in the post-spring bloom period in Disko Bay, western Greenland. Mar Ecol Prog Ser 359:151-160

Tiselius P, Andersen Borg CM, Hansen BW, Hansen PJ, Nielsen TG, Vismann B (2008) High reproduction, but low biomass: mortality estimates of the copepod Acartia tonsa in a hyper-eutrophic estuary. Aquat Biol 2:93-103

Tsuda A (1994) Starvation tolerance of a planktonic marine copepod Pseudocalanus newmani Frost. J Exp Mar Biol Ecol 181:81-89

Twombly S, Wang GM, Hobbs NT (2007) Composite forces shape population dynamics of copepod crustaceans. Ecology 88:658-670

Wang SB, Houde ED (1995) Distribution, relative abundance, biomass and production of bay anchovy Anchoa mitchilli in the Chesapeake Bay. Mar Ecol Prog Ser 121:27-38

Weikert H (1977) Copepod carcasses in the upwelling region south of Cap Blanc, NW Africa. Mar Biol 42:351-355

Appendix 1. Derivation of Eqs. (3) \& (4)

Based on the modifications to the VLT approach proposed in Hirst et al. (2007), we have proposed new equations to estimate predatory mortality (Eqs. 3 and 4). The concept behind these equations is that live copepods and intact carcasses both represent 'survivors' of predatory mortality. Eqs. (3) \& (4) represent the mathematical solutions to modifications of Aksnes \& Ohman (1996) their Eqs. (1) to (6). The number of individuals (live and dead) in the first stage $i\left(A_{i}\right)$ is modified to be:

$$
\begin{aligned}
A_{i} & =\rho_{i}\left[\pi_{1} \int_{x-s_{i}}^{x} \mathrm{e}^{-\delta_{i}(x-t)} \mathrm{d} t+\pi_{2} \int_{x-\tau}^{x} \mathrm{e}^{-\delta_{i}(x-t)} \mathrm{d} t\right] \\
& =\frac{\rho_{i}\left(1-\pi_{1} \mathrm{e}^{-\delta_{i} S_{i}}-\pi_{2} \mathrm{e}^{-\delta_{i} \tau}\right)}{\delta_{i}}
\end{aligned}
$$

where $\rho_{i}$ is the recruitment rate to Stage $i_{i} \pi_{1}$ and $\pi_{2}$ are the proportions live and dead, respectively, in Stage $i_{i} S_{i}$ is the duration of Stage $i_{i} \tau$ is the duration of carcasses in the water column (carcass turnover time); and $\delta_{i}$ is the predatory mortality rate. This equation states that the total number of individuals (live and dead) in Stage $i$ on Day $x$ is equal to the proportion of those recruited over the last $s_{i}$ days that are alive and have survived predatory mortality, plus the proportion of those recruited over the last $s_{i}$ days that are carcasses but have 'survived' predatory mortality.

The number of individuals in the second Stage $i+1\left(A_{i+1}\right)$ for non-adult stages is modified to be:

$$
\begin{aligned}
A_{i+1} & =\rho_{i+1}\left[\pi_{3} \int_{x-s_{i+1}}^{x} \mathrm{e}^{-\delta_{i+1}(x-t)} \mathrm{d} t+\pi_{4} \int_{x-\tau}^{x} \mathrm{e}^{-\delta_{i+1}(x-t)} \mathrm{d} t\right] \\
& =\frac{\rho_{i+1}\left(1-\pi_{3} \mathrm{e}^{-\delta_{i+1} S_{i+1}}-\pi_{4} \mathrm{e}^{-\delta_{i+1} \tau}\right)}{\delta_{i+1}}
\end{aligned}
$$

where $\rho_{i+1}$ is the recruitment rate to Stage $i+1 ; \pi_{3}$ and $\pi_{4}$ are the proportions live and dead, respectively, in Stage $i+1$; $S_{i+1}$ is the duration of Stage $i+1 ; \tau$ is the carcass turnover time; and $\delta_{i+1}$ is the predatory mortality rate. Recruitment to Stage $i+1$ is based on recruitment and stage-specific survival of Stage $i$ as:

$$
\rho_{i+1}=\pi_{1}\left(\rho_{i}\right)\left(\mathrm{e}^{-\delta_{i} s_{i}}\right)
$$

Recruitment to Stage $i+1$ does not include information on proportion dead because unlike the case of non-hatching eggs (Hirst et al. 2007), for which a very long egg development time was assumed, dead animals in Stage $i$ will never develop to Stage $i+1$.

In the special case of adults, the equation describing the number of individuals does not include removal of adults through development to the next stage (Aksnes \& Ohman 1996). Therefore, the number of individuals in the second stage when this is the adult stage $q\left(A_{q}\right)$ is modified to be:

$$
\begin{aligned}
A_{q} & =\rho_{q}\left[\pi_{3} \int_{-\infty}^{x} \mathrm{e}^{-\delta_{q}(x-t)} \mathrm{d} t+\pi_{4} \int_{x-\tau}^{x} \mathrm{e}^{-\delta_{q}(x-t)} \mathrm{d} t\right] \\
& =\frac{\rho_{q}\left(1-\pi_{4} \mathrm{e}^{-\delta_{q} \tau}\right)}{\delta_{q}}
\end{aligned}
$$

where $\rho_{q}$ is the recruitment rate to Stage $q_{i} \pi_{3}$ and $\pi_{4}$ are the proportions live and dead, respectively, in Stage $q_{i} \tau$ is the carcass turnover time; and $\delta_{q}$ is the predatory mortality rate. Recruitment to Stage $q$ is based on recruitment and stagespecific survival of Stage $q-1$ (equivalent to $i$ ) as:

$$
\rho_{q}=\pi_{1}\left(\rho_{i}\right)\left(\mathrm{e}^{-\delta_{i} S_{i}}\right)
$$

Combining Eqs. (A15), (A16) and (A17), and assuming a shared predatory mortality rate for the stages in question $\left(\delta_{i}=\delta_{i+1}\right)$, the ratio of abundances of 2 juvenile stages ( $i$ and $i+1)$ becomes:

$$
\frac{A_{i}}{A_{i+1}}=\frac{1-\pi_{1} \mathrm{e}^{-\delta s_{i}}-\pi_{2} \mathrm{e}^{-\delta \tau}}{\pi_{1}\left(\mathrm{e}^{-\delta s_{i}}\right)\left(1-\pi_{3} \mathrm{e}^{-\delta s_{i+1}}-\pi_{4} \mathrm{e}^{-\delta \tau}\right)}
$$

which is equivalent to Eq. (3) in the 'Methods' section.

Similarly, by combining Eqs. (A15), (A18) and (A19), and assuming a shared predatory mortality rate for the stages in question, the ratio of abundances of a juvenile stage $(q-1$, which is equivalent to $i$ ) to the adult stage $(q)$ becomes:

$$
\frac{A_{i}}{A_{q}}=\frac{1-\pi_{1} \mathrm{e}^{-\delta s_{i}}-\pi_{2} \mathrm{e}^{-\delta \tau}}{\pi_{1}\left(\mathrm{e}^{-\delta s_{i}}\right)\left(1-\pi_{4} \mathrm{e}^{-\delta \tau}\right)}
$$

which is equivalent to Eq. (4) in the 'Methods' section. 